\title{
Single stage Anterior Sagittal Anorectoplasty (ASARP) for Anorectal Malformations with Vestibular Fistula and Perineal Ectopic Anus in Females: A New Approach
}

\author{
Chaudhary RP ${ }^{1}$, Thapa $\mathrm{B}^{2}$, Thana $\mathrm{S}^{3}$, Singh $\mathrm{PB}^{4}$ \\ ${ }^{1}$ Dr. Ramananda Prasad Chaudhary, MBBS.MS. Consultant Pediatric Surgeon, ${ }^{2}$ Dr. Bijay Thapa, ${ }^{3}$ Dr. Santosh Thana, \\ ${ }^{4}$ Dr. Pradeep B. Singh. Medical Officers, Kanti Children's Hospital, Kathmandu, Nepal.
}

Address for Correspondence: Dr. RP Chaudhary, E-mail: drchaudharyrp@hotmail.com

\begin{abstract}
Introduction: Despite a better understanding of the embryology, anatomy of anorectal malformations and of the physiology of continence, the management of children born with imperforate anus continues to be a surgical challenge and is still fraught with numerous complications and often leads to less than perfect qualitative results. Pediatric patients with recto-vestibular fistula have good prognoses in terms of bowel function when properly treated. Aim \& Objective: The study was designed to assess the surgical morbidity of single stage Anterior Sagittal Anorectoplasty (ASARP). Methodology: This prospective study was carried for a period of 26 months. It included a total of 48 female patients (aged $0-14$ years) with diagnosis of Anorectal Malformations (ARM) with vestibular fistula or perineal ectopic anus. In ASARP, Patient in lithotomy position, the anterior portion of sphincter muscles were cut through a midline perineal skin incision, rectum was separated from the vagina \& then rectum was pulled through the center of these muscles. The perineal body was reconstructed and the normal appearance of perineum was achieved. Results: Short-term surgical outcome was satisfactory in all cases. No one needed colostomy. Conclusion: Single-stage ASARP is a good approach in experience hands for ARM with vestibular fistula and perineal ectopic anus in females and thereby complications and time involved in staged procedures including colostomy can be avoided.
\end{abstract}

Key words: Anterior sagittal anorectoplasty, anorectal malformations, perineal ectopic anus, vestibular fistula.

\section{Introduction}

$\mathrm{V}$ estibular fistula and perineal ectopic anus are the most common anorectal malformations in female children ${ }^{1}$. Imperforate anus without a fistula is a rather unusual defect ${ }^{2}$. Despite a better understanding of the embryology, anatomy of anorectal malformations and of the physiology of continence, the management of children born with imperforate anus continues to be a surgical challenge and is still fraught with numerous complications and often leads to less than perfect qualitative results ${ }^{3}$. Pediatric patients with rectovestibular fistula have good prognoses in terms of bowel function when properly treated. The bowel opens immediately behind the hymen in the vestibule of the female genitalia. Immediately above the fistula, rectum and vagina are separated by a thin common wall. These patients usually have well-developed muscles and a normal sacrum and nerves. A meticulous inspection of the newborn genitalia is needed for the diagnosis ${ }^{2}$.

The conventional surgical treatment has not always been satisfactory. The previously used surgical techniques include cutback, perineal anal transplant, Y$\mathrm{V}$ plasty, sacroperineal repair, and colostomy followed by minimal posterior sagittal anorectoplasty. These procedures have been limited by incomplete anatomic exposure, blind tunneling of the rectum, lack of 
reconstruction of the perineal body, need for a colostomy and a displeasing appearance of the perineum, with anterior migration of the anus in the long term. These limitations have been offset by ASARP ${ }^{1,3}$.

The optimal surgical repair should allow easy access to the fistula, minimize the dissection to spare pelvic nerves, guide the rectal pouch through all the muscles of continence, restore a physiological anorectal angle, create good anal opening and take advantage of all existing structures. Most contemporary techniques attempt to preserve the major elements of continence, often at the cost of "Lesser" factors, increased dissection or poorer exposure ${ }^{4}$.

de Vries and Pena in 1982 reported posterior sagittal anorectoplasty as an operative procedure for high or intermediate imperforate anus. By the reference to the idea of this operative procedure, Okada et al devised a new approach, anterior sagittal anorectoplasty (ASARP) for repair of a vestibular fistula, in which, in the lithotomy position, sphincter muscles are cut from the anterior aspect longitudinally through a median perineal skin incision and then the rectum is passed through the central portion of the sphincter muscle ${ }^{5}$. A number of pediatric surgeons repair this defect, primarily without a protective colostomy ${ }^{6}$.

\section{Methodology}

In this prospective study, primary ASARP was performed from September 2004 to March 2009 (55 months) on 48 patients of anoretal malformations with vestibular fistula or perineal ectopic anus in Kanti Children's Hospital and Ishan Children's Nursing and Maternity Home (Table 1) their age range was from neonates (3 days) to five years old children (Table 2).

Table 1: Showing the diagnosis of Patients.

\begin{tabular}{|l|c|}
\hline Diagnosis & No. of Patients \\
\hline Vestibular Fistula & 44 \\
\hline Perineal Ectopic Anus & 4 \\
\hline
\end{tabular}

All patients who underwent ASARP were included in this study. Patients with anorectal malformations with colostomy, with prematurity, with septicemia, with birth asphyxia and patients with major defects making them unfit for GA were excluded from the study.

Table 2: Showing the Age Distribution of Patients.

\begin{tabular}{|l|c|}
\hline Age & No. of Patients \\
\hline Neonates & 15 \\
\hline $1-12$ months & 25 \\
\hline$>1$ year & 8 \\
\hline
\end{tabular}

Surgical anatomy: In normal individual, the voluntary striated muscle structures responsible for fecal control are represented by funnel-like muscle structure. Anatomically, the levator ani (also called the pelvic diaphragm) is arbitrary divided into three striated muscle groups: ileococcygeus, pubococcygeus and puborectalis. Functionally \& anatomically, the puborectalis is therefore more likely linked to the external anal sphincter as a part of the striated muscle complex ${ }^{7}$. Often acting as a single unit,they are sometimes referred to as the striated muscle complex ${ }^{8}$. Apart from this, the superficial and deep transverse perinei muscle muscle fuse in the midline to form perineal body along with the anterior most fibers of the external sphincter.

In patients with a vestibular fistula, the development of the sphincteric muscle is normal and the 'anus' or 'fistula' opens into the vestibule between the hymen and the fourchette, surrounded by moist mucous membrane rather dry skin ${ }^{9}$. In cases of perineal ectopic anus, only the postetior aspect of the anorectum is enclosed by the vertical muscle complex. They attributed the constipation seen with this defect to a 'shelf' effectof the 'levator ani, or pelvic floor behind the abnormal anterior opening ${ }^{10}$.

Operative Technique: Patients were investigated to find out any associated anomalies. Pre-operative preparations; They were treated for constipation with laxatives (Lactulose and fistula irrigation with normal saline). They were kept nothing per oral for 48 hours in infants and older children and 24 hours in neonates. Oral antibiotics (Erythromycin $50 \mathrm{mg} / \mathrm{kg}$ and Metronidazole $20 \mathrm{mg} / \mathrm{kg}$ in divided doses) were started 48 hours before surgery. The operation was performed under general anaesthesia along with caudal block. Proposed anal site was determined by the anal mark and confirmed by the use of an electrostimulator. With patient in lithotomy position, a Foley catheter was passed through urethra into the bladder before surgery. Pre-operative calculated doses of i.v. antibiotics (Cephalosposin, Gentamicin \& Metronidazole) were given with the induction of anaesthesia.

A circular incision was made in the mucocutaneous junction at the opening of the fistula and extended posteriorly along the median line to reach the anal dimple. Several fine silk traction sutures were inserted around the fistula orifice. Through the incision, the fistula (anorectum) was first dissected free bluntly little by little from surrounding tissues with meticulous care being taken not to cause damage to the musculature enclosing the rectum. The rectum was separated from the posterior wall of the vagina by sharp dissection; side by side retrorectal dissection is also done. The length of 
the rectal tube to be dissected was 4 to $5 \mathrm{~cm}$. Bleeding vessels were controlled by electro- coagulation. The first muscle to come in sight was the superficial external sphincter muscle; next to come was the deep external sphincter muscle. The latter muscle soon joined the longitudinal muscles that spread out in a fan-shaped pattern. Behind these thin muscles lied puborectalis muscle, enclosing the rectum and was definitely palpable. Posterior part of those fan-shaped longitudinal muscle fibers and puborectalis muscle was carefully preserved.

Next, the dissected rectal tube was mobilized backward to be placed at the center of the fan-shaped muscles. Anterior ends of the fan shaped muscle fibers were apposed and sutured by interrupted suture with several stitches of 4-0 vicryl suture beginning from the lower depths upward and outward. The rectum was fixed to the deep external sphincter muscles over its entire circumference by 4-0 interrupted stitches. Sutures were placed between the rectal stump and surrounding skin by about 12 -16 stitches of 4-0 vicryl (Anoplasty). The neoanus should allow for the initial passage of at least number 10, Hegar dilator in neonates. Then, subcutaneous adipose and connective tissues extending

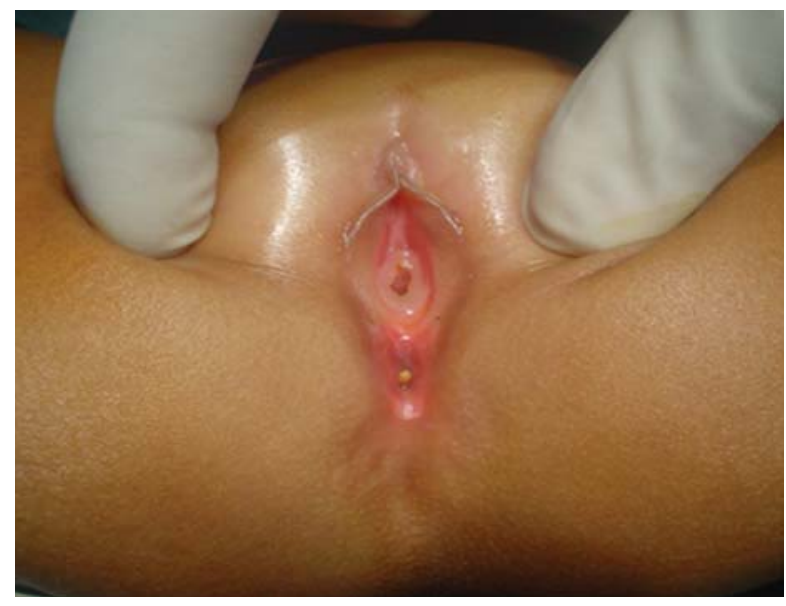

Fig 1: Showing ARM with Vestibular Fistula.

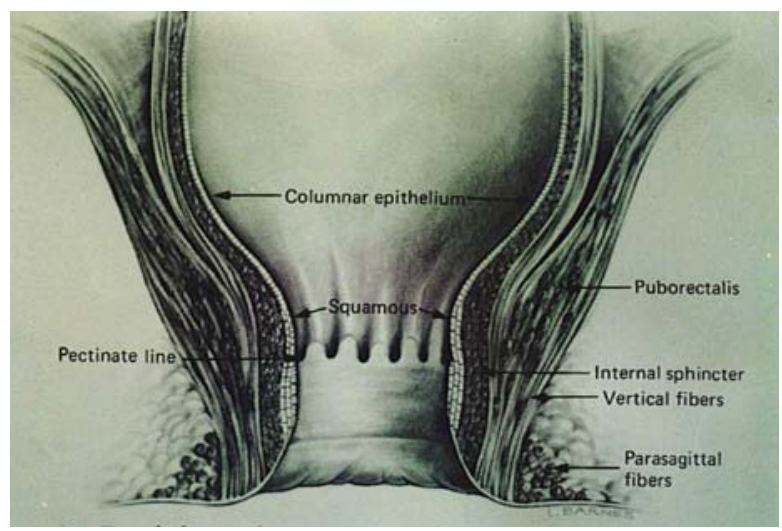

Fig. 3: Detailed normal anorectal anatomy, coronal view (Pena 1990). up to the vaginal wall were approximated and sutured with interrupted 4-0 vicryl. The operation ended with closure of the surgical wound by suturing the perineal skin intradermally, with resultant creation of the perineal body.

Post-operatively, patients were managed by Analgesic for infants was Paracetamol drop (15 mg / kg / dose) and that for others was intramuscular pethidine (1- $1.5 \mathrm{~kg} /$ dose) 6 hourly. Foley catheter was kept in situ up to $5^{\text {th }}$ postoperative days for better perineal care. Aqeuous povidone iodine solution was applied over operated wound and neoanus several times a day. Patient was kept nothing per oral for 4 days. Oral feeding was started on $5^{\text {th }}$ POD. Catheter was removed on $5^{\text {th }}$ post operative day. Intravenous antibiotics were continued up to $5^{\text {th }}$ postoperative days, followed by oral cephalosporin for 2 more days. Majority of the patients were discharged within 6 to 8 days of surgery unless indicated for some reasons. Parents were informed about the planned schedule of follow up and anal dilatation was started on $14^{\text {th }}$ post operative day continued up to approximately 8 months as per Pena's schedule ${ }^{12}$. The parents were demonstrated how to perform dilatation at home.

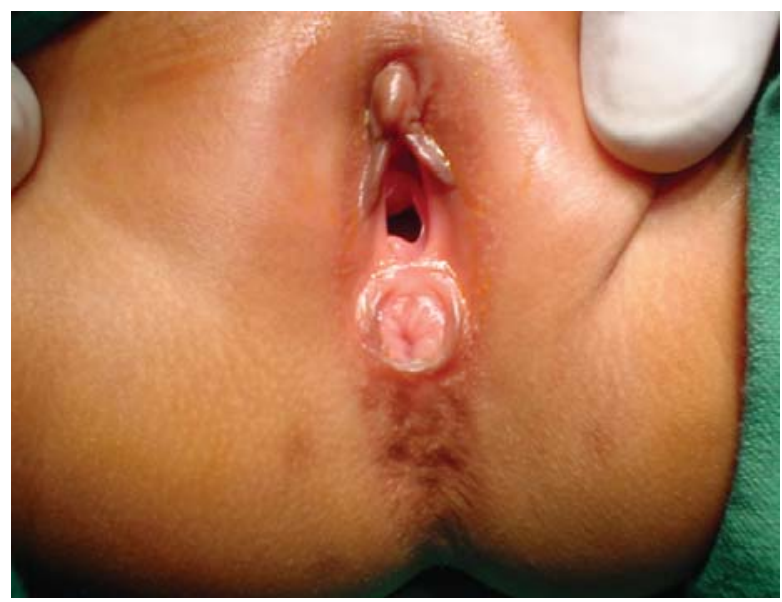

Fig 2: Showing ARM with Perineal Ectopic Anus

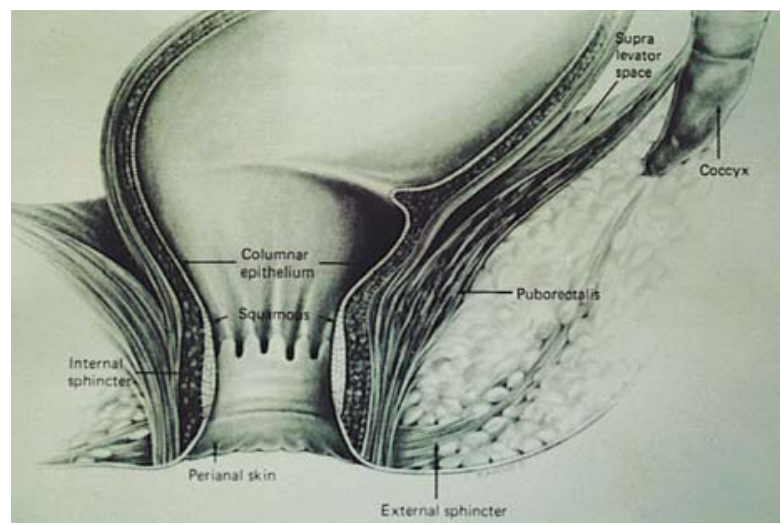

Fig. 4: Detailed normal anorectal anatomy, sagittal view (Pena 1990). 


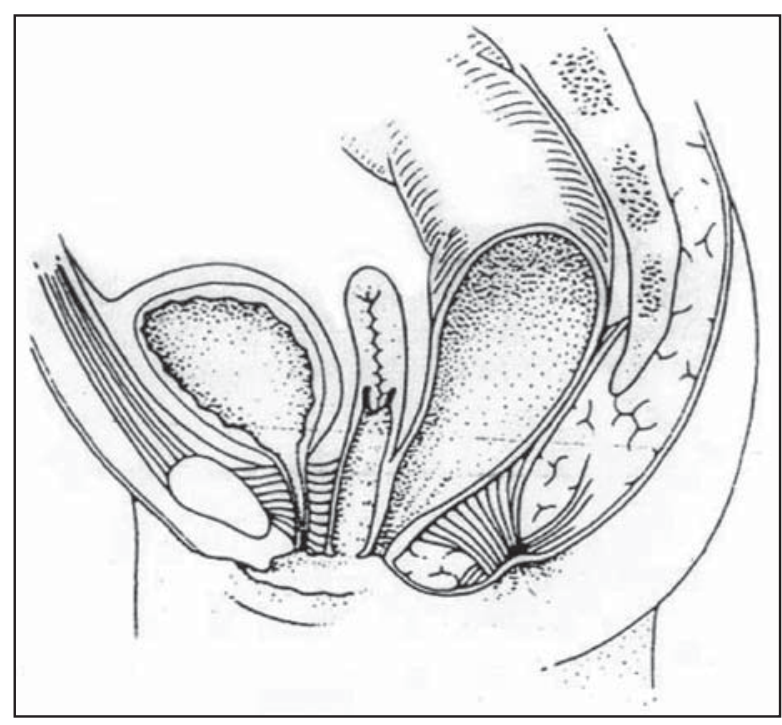

Fig. 5: Vestibular Fistula (Pena 1995).

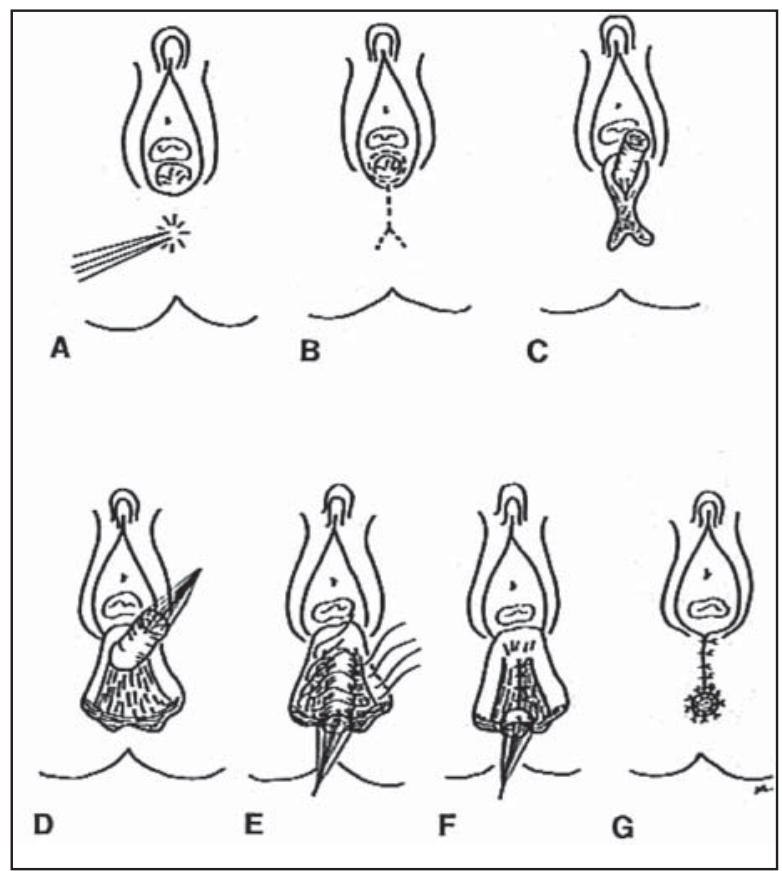

Fig. 7: Operative technique: Anterior Sagittal Anorectoplasty (Okada et al 1992).

\section{Results}

Anterior sagittal anorectoplasty was performed on 32 female patients for anorectal malformations with vestibular fistula or perineal ectopic anus from November, 2002 through June, 2004.

During perineal examinations following findings were noted: type of fistula, look of perineum, anal dimple and mark, anal pigmentation, midline groove, sacrum and perineal muscle contraction. 16 (33.33\%) patients had associated anomalies.

In all cases, operation was performed following the forementioned procedures after confirming the site of

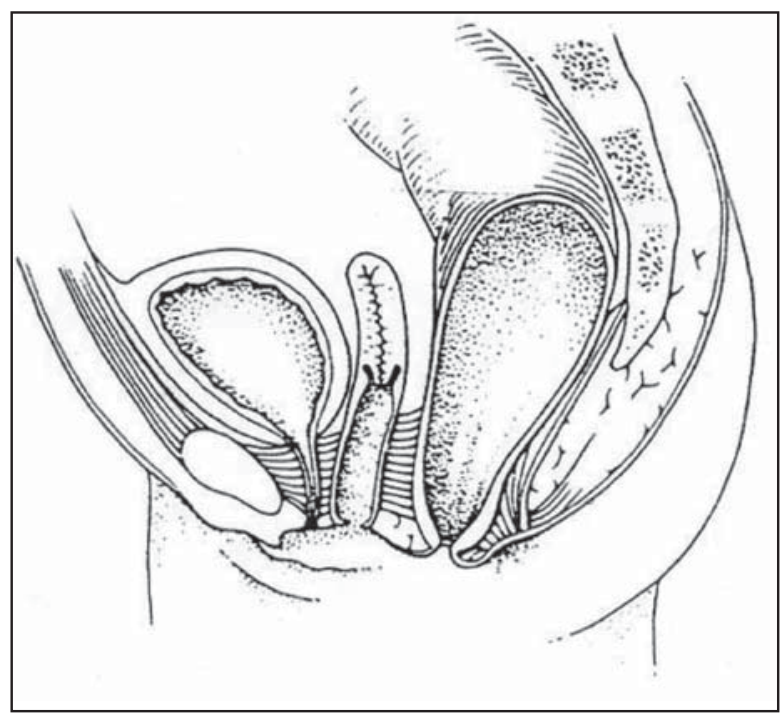

Fig. 6: Female Perineal Anus (Pena 1995).

anus by nerve stimulator. One patient who developed post operative complication of perianal excoriation, recovered well after 2 weeks of surgery. On assessment of results (Table 4), the site, size and appearance of the neoanus was normal in all cases. The frequency of bowel movement was 1-2 times in 40 patients and 2-3 times in 8 patients. The consistency of fecal matter was normal (formed or semisolid) in all 48 cases. None of the patients in this study, suffered from constipation and soiling. All the parents of children were satisfied with the outcome.

Follow up period was minimum of 6 months to 55 months. Accordingly, the patient visited the hospital as follows: $1^{\text {st }}$ follow up at 14 days of surgery, $2^{\text {nd }}$ follow up at 1 month of surgery and $3^{\text {rd }}$ follow up at 3 months of surgery. During each visit, following points were noted: i) Neoanual size, site and appearance. ii) Perineal wound. iii) Voluntary Bowel movements. iv) Fecal incontinence. v) Constipation. vi) Any complications.

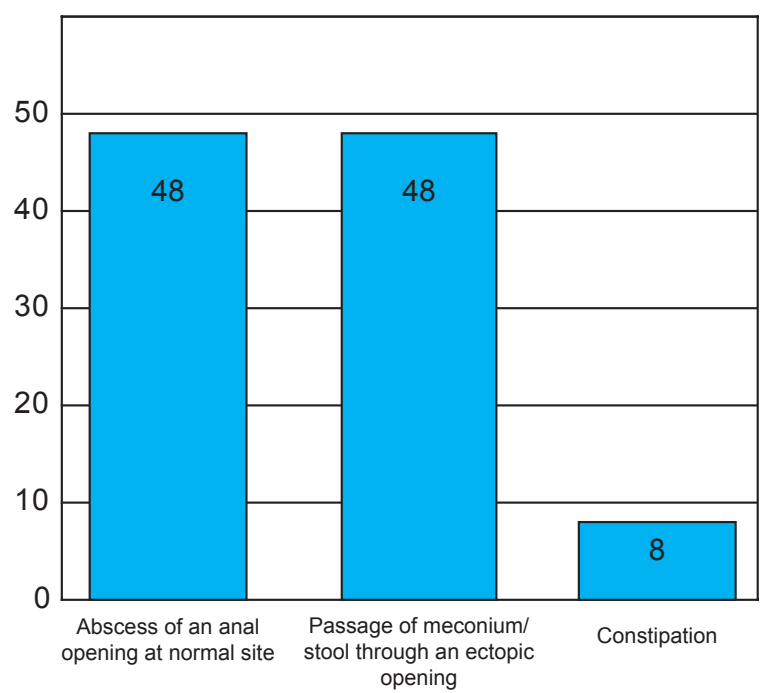

Fig. 8: Clinical presentations of the patients 
Table 3: Associated anomalies

\begin{tabular}{|l|l|c|}
\hline Associated Anomalies & Number of Patients \\
\hline Urogenital defects & $\begin{array}{l}\text { Hydronephrosis (3 cases), ), Indirect Inguinal hernia (2 cases) Dys- } \\
\text { plastic kidney(1 case) and renal agenesis (1 case) VUR (1 case) }\end{array}$ & $8(16.66 \%)$ \\
\hline Cardiac defects & VSD (3 cases), TOF with complex anomaly (1 case) & $4(8.33 \%)$ \\
\hline Skeletal defects & Polydactyly (2 cases), Rudimentary index finger (1 case) & $3(6.25 \%)$ \\
\hline Others & Talipes Equino-Varus (1 case) & $1(3.13 \%)$ \\
\hline
\end{tabular}

Table 4: Showing the results of ASARP

\begin{tabular}{|c|c|c|c|}
\hline \multirow{7}{*}{ Neoanus } & \multirow{2}{*}{ Appearance } & Round & $48(100 \%)$ \\
\hline & & Oval & - \\
\hline & \multirow{2}{*}{ Site } & Correct & $48(100 \%)$ \\
\hline & & Incorrect & - \\
\hline & & & \\
\hline & \multirow{2}{*}{ Size } & Adequate & $48(100 \%)$ \\
\hline & & Stenosis & - \\
\hline \multirow{2}{*}{\multicolumn{2}{|c|}{ Frequency Of Defaecation (Per Day) }} & 1-2 Times & $40(83.33 \%)$ \\
\hline & & 2-3 Times & $8(16.66 \%)$ \\
\hline \multirow{2}{*}{\multicolumn{2}{|c|}{ Consistency }} & Normal & $48(100 \%)$ \\
\hline & & Loose & - \\
\hline \multirow{2}{*}{\multicolumn{2}{|c|}{ Constipation }} & Absent & $348(100 \%)$ \\
\hline & & Present & - \\
\hline \multirow{2}{*}{\multicolumn{2}{|c|}{ Soiling }} & Absent & $48(100 \%)$ \\
\hline & & Present & - \\
\hline \multirow{2}{*}{\multicolumn{2}{|c|}{ Neoanal Retraction }} & Absent & $48(100 \%)$ \\
\hline & & Present & - \\
\hline \multirow{2}{*}{\multicolumn{2}{|c|}{ Parental Reaction }} & Satisfied & $48(100 \%)$ \\
\hline & & Unsatisfied & - \\
\hline
\end{tabular}

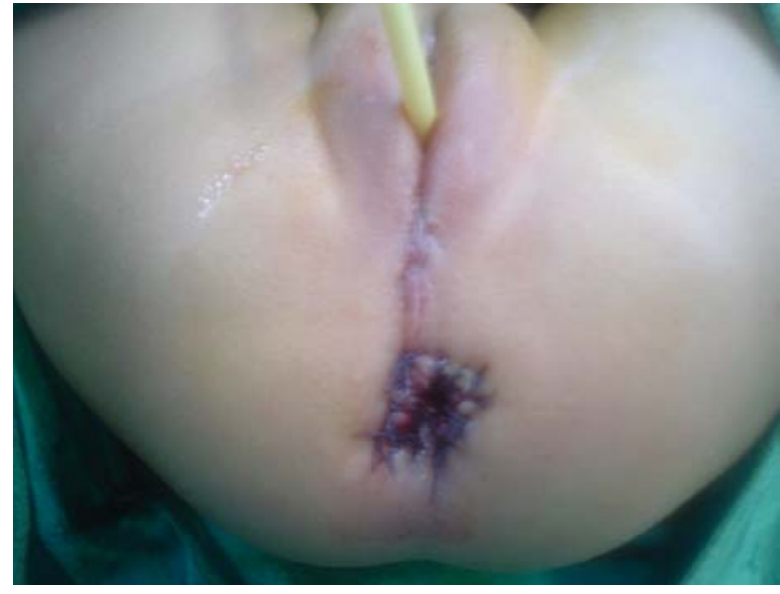

Fig. 9: Showing the perinium after ASARP

\section{Discussion}

The technique described herein has several advantages over the posterior sagittal approach and other anterior perineal techniques. Conceptually, continence is dependent on the integrated function of the puborectalis, the internal and external sphincters, normal sensation of rectal fullness, and normal discrimination by the anoderm ${ }^{13}$. This technique has the advantages of the anterior perineal approach popularizes by Mollard $^{14,15}$. Previous operative procedures like cut back operation or its modification ' $\mathrm{V}-\mathrm{Y}$ plasty' for the repair of anovestibular fistula, however have the disadvantage of the contamination of the vagina and urethra with consequent vaginitis and urethritis often results and soiling or staining due to mucosal involvement may occur at times ${ }^{16,17}$.

The limitations like incomplete anatomic exposure, blind tunneling of the rectum, lack of reconstruction of the perineal body, need for a colostomy and a displeasing appearance of the perineum, with anterior migration of the anus in the long term have been offset by ASARP; colostomy is obviated, can be performed even in neonates, mobilizqtion of the rectum is visualized, only the anterior aspect of the sphincteric muscle complex is divided, continence mechanism is preserved (puborectalis muscle is preserved), there is minimal dissection, allows better anatomic exposure for separation of rectum from vagina, sphincter muscles and the perineal body are accurately reconstituted, easy- to- perform approach of salient repairing efficacy. The extensive preoperative and postoperative measures advocated by Okada et $\mathrm{al}^{18}$ weren't needed in this study. Chatterjee advocated use of a colostomy if the patient is over 5 years of age or in cases of mega rectum or a small fistula that prevents bowel preparation ${ }^{19}$. But no colostomy was performed in these cases too and there weren't any serious complications. None of the 2 (6.25\%) 
patients who suffered peroperative complications of vaginal wall tear developed further complications. One patient who suffered post-operative complication (of perianal skin excoriation improved with local application of zinc oxide paste.

In this series complications were less than Wakhlu et al (1996) series (11.53\%) but higher than Okada et al (1992) \& Okada et al (1993) series where, in all cases, the postoperative course was uneventful without any wound infection or laceration and their bowel habits \& anorectal discharge control were nearly satisfactory in all the infants. Short-term surgical outcome was acceptable in all 48 cases and all patients had normal size, round shaped neoanus at normal site.

There is evidence that the cortical intergration of somatosensory input from the anal skin may be lost after the third or fourth month of life ${ }^{20}$ if unused. This strongly supports early repair of high imperforate anus, enabling the development of normal stooling patterns at the appropriate time. When an anterior sagittal incision is used in a neonate, the preoperative differentiation between low, intermediate and high types becomes less necessary ${ }^{21}$. Colostomy or not, the important thing is to establish normal stooling as soon as possible. The modern trend is to operate on newborns with anorectal malformations, primarily without a protective colostomy. Even more ambitious and bold is the tendency to repair these babies primarily without a protective colostomy and laparoscopically ${ }^{11}$.

I believe that this technique makes maximal use of native tissues, with minimal dissection and optimal reconstruction of this deformity. This study demonstrates that single stage ASARP can be performed with acceptable surgical outcome in cases of ARM with vestibular fistula or perineal ectopic anus in female. I would like to follow up these patients to see the longterm outcome of the approach.

\section{Conclusion}

Outcome of single-stage Anterior sagittal anorectoplasty is good and is an acceptable approach for ARM with vestibular fistula or perineal ectopic anus in female and thereby complications and time involved in staged procedure including colostomy can be avoided.

Acknowledgement: None

Funding: Nil

Conflict of interest: None

\section{References}

1. Wakhlu A, Pandey A, Prasad A, Kureel SN, Tandon RK, Wakhlu AK. Anterior Sagittal Anorectoplasty for Aorectal Malformatios and Perineal Trauma in the Female Child. J Pediatr Surg.1996; 31:12361240.

2. PenaA. ImperforateAnusand Cloacal Malformations in Pediatric Surgery, 3rd. edn, ed. K.W.Ashcraft, W.B.Saunders company, Philadelphia, 2000: 473492.

3. Smith ED. The bath Water Needs Changing, But Don't Throw out the Baby: An overview of Anorectal Anomalies. J. Pediatr Surg. 1987; 22: 335-348.

4. Yazbeck S, Luks FI, St-vil D. Anterior Perineal Approach and Three-Flap Anorectoplasty for Imperforate Anus: Optimal Reconstruction With Minimal Destruction. J. Pediatr Surg. 1992; 27: 190-195.

5. Okada A, Shinkichi K, Imura K, Fukuzawa M, Kubota A, Yagi M, Azuma T, Tsuji H. Anterior Sagittal Anorectoplasty for Rectovestibular and Anovestibular Fistula. J.Pediatr Surg. 1992; 27: 85-88.

6. Moore TC. Advantages of Performing the Sagittal Anoplasty Operation for Imperforate Anus at Birth. J. Pediatr Surg. 1990; 25: 276-277.

7. Stafford, P.E.W. Other disorders of the Anus and Rectum, Anorectal Function in Pediatric Surgery, 5th. edn, vol-2, eds. J.A. O'Neill,Jr., M.I. Rowe, J.L.Grosfeld, E.W.Fonkalsrud, \& A.G.Coran, Mosby-Year Book, St.Louis, 1998; pp. 1449-1460.

8. Weinberg G, Boley SC. Anorectal continence and Management of constipation in Pediatric Surgery, 3rd. edn, ed. K.W. Ashcraft, W.B.Saunders Company, Philadelphia, 2000; pp.502-510.

9. Freeman NV. Anorectal Malformations', in Surgery of the Newborn, eds. N.V.Freeman, D.M. Burge, M.Griffiths and P.S.J.Maline, Churchill Livingstone, Edinburgh, 1994; pp. 171-199.

10. de Vries PA. Complications of surgery for congenital Anomalies of the Anorectum in Complications of Pediatric surgery, eds. P.A.deVries, S.R.Shapiro, John Wiley \& sons, New York, 1982; pp. 233-262.

11. Pena A., 'An atlas of Surgical Management of Anorectal Malformations', Spring-Verlag, Newyork, 1990 pp. 1- 95. 
12. Pena A. 'Anorectal anomalies', in Newborn Surgery, 2nd. edn, ed. P. Puri, Arnold, London, 2003; pp. 535-552.

13. Holschneider AM, Freeman NV. Anatomy and function of the normal rectum and anus, in Stephen FD, Smith ED, Paul NW eds. Anorectal Malformations in Children: Update 1988, NY Liss, Newyork,1988 pp. 125-154.

14. Mollard P, Marechal JM, de Beaujeu MJ. Surgical Treatment of High Imperforate Anus with Definition of the Puborectalis Sling by an Anterior Perineal Approach. J. Pediatr Surg. 1978; 13: 499-504.

15. Mollard P, Soucy P, Louis D et al. Preservation of Infralevator structures in imperforate anus repair. J Pediatr Surg, 1989; 27: 185-189.

16. Ishihara M, Morita $\mathrm{K}$. Techniques and indication of the cut back procedure and Potts method for low deformities. Jpn J Pediatr Surg. 1981; 13: 11991204.
17. Nixon HH. Review of anorectal anomalies. J R Soc Med, 1984(suppl); 77:27-29.

18. Okada A, Tamada H, Tsuji H, Azuma T, Yagi M, Kubota A, Kamata S. Anterior Sagittal Anorectoplasty as a Redo Operation for Imperforate Anus. J.Pediatr Surg. 1993; 28: 933-938.

19. Chaterjee SK. Lesions in the Wingspread list management in the neonatal period, in Chaterjee SK ed: Anorectal Malformations - A Surgeons Experience, Oxford University, New Delhi, India 1991 pp 48-64.

20. Freeman NV, Burge DM, Soar JS et al. Anal Evoked potentials. Z Kinderchir, 1980; 31:22-30.

21. Sigalet DL, Laberge JM, Adolph VR, Guttman FR. The Anterior Sagittal Approach for High Imperforate Anus: A simplification of the Mollard Approach. J. Pediatr Surg. 1996; 31:625-629. 